\title{
The Importance of Location, Location, Location: As True for Rhodococcus fascians as for Real Estate
}

T. Sawyer ${ }^{1}$ and M.L. Putnam ${ }^{2}$

1. Electron Microscopy Facility, Oregon State University, Corvallis, OR, USA

2. Botany and Plant Pathology, Oregon State University, Corvallis, OR, USA

Rhodococcus fascians is a Gram-positive pleomorphic bacterial pathogen of plants which causes growth deformities known as leafy galls (Figure 1). The majority of plants affected are those produced for amenity use, hence grossly malformed plants, for which there is no cure, must be destroyed at the nursery, leading to losses up to and exceeding hundreds of thousands of dollars per nursery on an annual basis

An epiphytic phase of the bacteria was first described in 1936 [1] by observation of inoculated pea seedlings thin-sectioned, stained, and examined under a compound light microscope. Much later, scanning electron microscopy [2] was used to determine where on the plant surface the bacteria were located, but the focus was on aerial structures. In neither study were bacteria observed in cell layers deep within the tissues or in the vascular system, nor is it known whether it is possible for $R$. fascians to systemically infect plants. Whether the bacteria can colonize roots is also unknown, although previous studies in our laboratory have shown that leafy galls form after inoculation of soil of pot-grown plants. It is important to understand whether $R$. fascians colonizes the vascular tissue or roots: if so, this would provide new insights into the infection process, epidemiology and management of disease caused by the bacteria. We are now examining the various organs and tissues of peas inoculated as seeds to determine the physical location of $R$. fascians cells within and on the plants.

Phaseolus vulgaris seeds were semi-immersed in a suspension of $10^{8}$ colony forming units (CFU) per $\mathrm{ml}$ of bacterial cells for one hour, then placed individually on a solid growth medium in glass test tubes and incubated under continuous light for two weeks, after which they were examined. Peas were inoculated with a pathogenic isolate, a non-pathogenic isolate, or sterile buffer.

After the infection period a $5 \mathrm{~mm}$ sections roots and stems were removed from the seed for scanning electron microscopy processing. Individual parts were chemically fixed in a modified Karnovsky formulation over night at 4C. Specimens were dehydrated in a serial solution of acetone from $10 \%-$ $100 \%$ in preparation for critical point drying. Samples were mounted on a stub, sputter coated and imaged with a Quanta 600 FEG scanning electron microscope, (FEI, Hillsboro, OR, USA).

Cells of $R$. fascians were clearly visible within the cortical cells of a pea root that had emerged after inoculation (Figure 2).

[1] M. Lacey, Ann. Appl. Biol. 23 (1936) pp. 743-751.

[2] K. Cornelis et al, MPMI 14 (2001) pp. 599-608. 


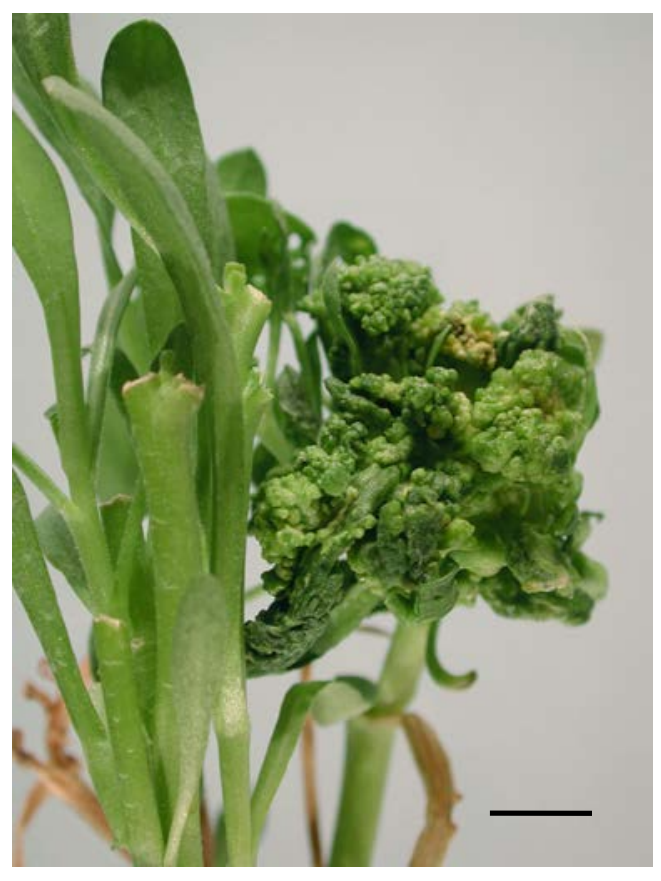

Figure 1. A leafy gall on a young Osteospermum plant. Bar $=1 \mathrm{~cm}$.
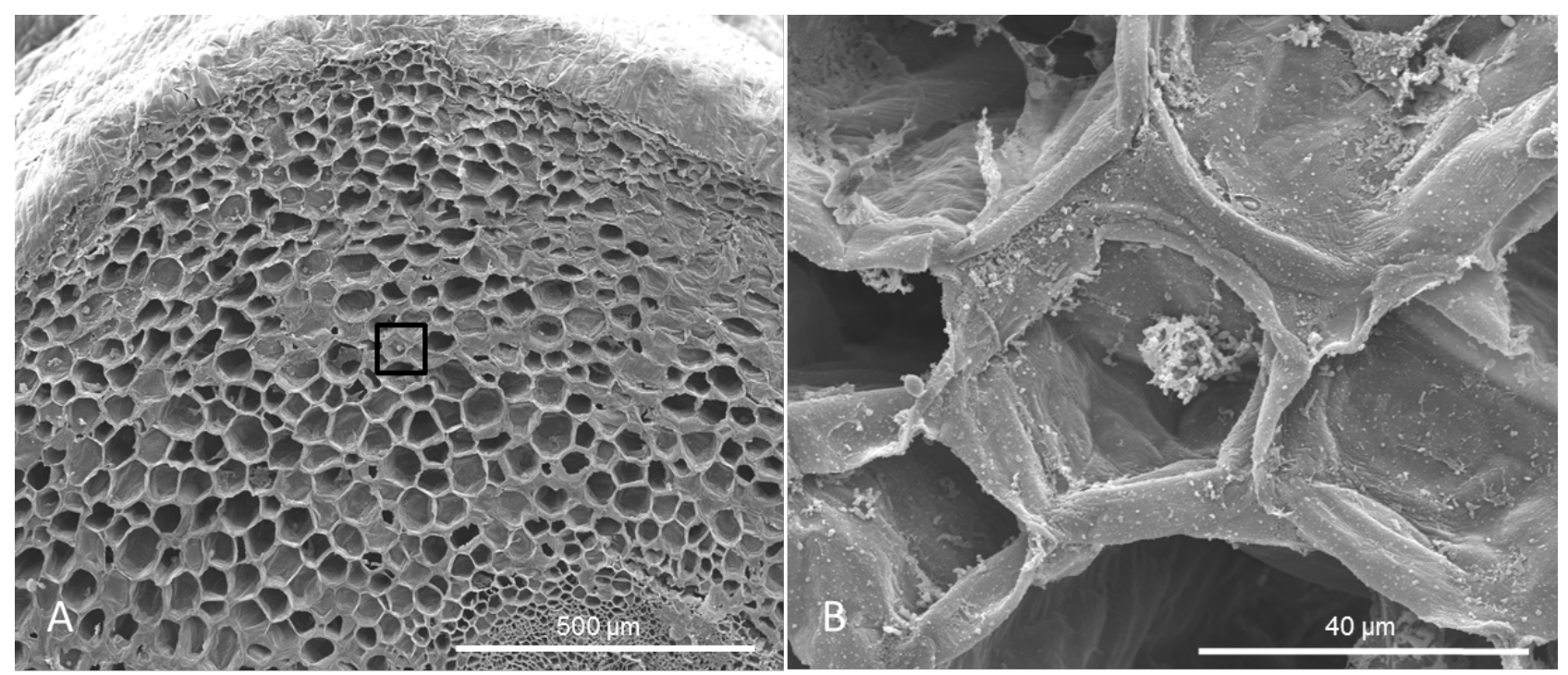

Figure 2. A cluster of $R$. fascians growing within the cortical cells of a pea root. A shows the location of the cells enlarged in $\mathrm{B}$. 